\title{
Application of C4.5 Algorithm for Simulation of Prediction of Victory in Acceptance of Several Prospective Employees
}

\author{
Preddy Marpaung \\ STMIK Pelita Nusantara, Jl. Iskandar Muda No. 1 Medan, 20154, Sumatera Utara-Indonesia 35142 \\ E-mail: preddy@gmail.com
}

\begin{abstract}
Employees as individual who work for employer, Based on agreement and work agrements both written and unwritten, to carry out a job in a certainposition or activityby obtaining compensation paid based on a certain period, Job adjustments or other Provisions applied by the employer. Including individuals who do woork in public office, and it can be assumed that employeses are all residents who can do work and get a salary every mount, Both at school and company and school also require several new employees who will be placed as teachers in the field of sport. Therefore we need method or method to indentify prospective new employees in the field of sport at school. This was done to get the creteria needed by the school. C4.5 Algorithm can be used to make predictions or clafication of prospective new employees who want to join ABC school using the concept of entropy and gain.
\end{abstract}

Keywords: C4.5 Algorithm method, for propective new school employees

\begin{abstract}
Abstrak- Pegawai adalah Orang pribadi yang bekerja pada pemberi kerja, berdasarkan perjanjian atau kesepakatan kerja baik secara tertulis maupun tidak tertulis, untuk melaksanakan suatu pekerjaan dalam jabatan atau kegiatan tertentu dengan memperoleh imbalan yang dibayarkan berdasarkan priode(akhir/awal bulan) tertentu, Penyelesaian pe kerjaan, atau ketentuan lainyang ditetapkan pemberi kerja,termasuk orang pribadi yang melakukan pekerjaan dalam jabatan negri, dan dapat diasumsikan bahwa pegawai adalah semua penduduk yang mampu melakukan pekerjaan dan mendapatkan gaji setiap bulan baik itu disekolah maupun perusahaan dan sekolah juga memerlukan beberapa pegawai baru yang akan ditempatkan menjadi guru dibidang olahraga. Oleh karna itu diperlukan cara atau metode untuk mengindentifikasi calon pegawai baru dibidang olahraga pada sekolah. Hal itu dilakukan untuk mendapatkan kreteria yang dibutuhkan oleh sekolah. Algoritma C4.5 dapat digunakan untuk melakukan prediksi dan klasifikasi terhadap calon pegawai baru yang ingin begabung ke sekolah $\mathrm{ABC}$ dengan menggunakan konsep entropy dan gain.
\end{abstract}

Kata Kunci: Metode Algoritma C4.5, Calon Pegawai Baru, Sekolah

\section{Pendahuluan}

Sekolah Merupakan salah satu komponen utama dalam kehidupan seseorang anak selain keluarga dan Secara umum sekolah adalah tempat dimana seorang guru diistimulasi untuk mengajar atau memberi contoh yang terbaik,[1] , Ada juga yang menyebutkan definisi sekolah adalah lembaga pendidikan yang dirancang secara khusus untuk mendidik siswa/siswi dalam pengawasan para pengajar atau guru, sedangkan menurut kamus Besar Bahasa Indonesia (KBBI), definisi sekolah adalah lembaga atau bangunan yang dipakai untuk aktivitas belajar dan mengajar sesuai dengan jenjang pendidikannya (SD,SLTP,SLTA)

Guru atau tenaga pengajar adalah unsur sekolah yang sangat penting karena tanpa adanya guru maka proses belajar-mengajar tidak akan terjadi Tenaga pengajar tersebut harus memenuhi kualifikasi tertentu agar dapat memberikan pengjaran kepada para peserta didik, temasuk juga guru olahraga yang banyak diminati oleh sekolahsekolah.

Adapun beberapa permasalahan yang sering muncul mengenai penerimaan calon pegawai baru dalam bidang olahraga yaitu sekolah sulit untuk mendapatkan pegawai baru yang update sangat antusias untuk membuat para siswa/siswi untuk mengikuti kegiatan olahraga di dalam sekolah tersebut. Dan dalam penelitian ini perlu ada nya Sistem Pendukung Keputusan dan metode yang dapat digunakkan untuk mengetahui beberapa pegawai yang terpilih oleh sekolah, untuk menjadi pegawai dalam bidang olahraga.

Dalam penentuan Penerimaan calon pegawai baru di sekolah diperlukan suatu penelitian dengan menggunakan metode algoritma $\mathrm{C} 4.5$ Untuk mengetahui siapa saja dari beberapa calon pegawai baru yang tepat untuk di jadikan menjadi guru di sekolah $\mathrm{ABC}$ yang akan ditempatkan di bagian olahraga, dan metode yang digunakan adalah metode Algoritma C4.5 karena memiliki perhitungan dengan menggunakan pohon keputusan dan metode ini sangat tepat untuk menentukan siapa saja yang dapat diterima oleh sekolah tersebut.

Ada beberapa Penelitian terdahulu yang sudah banyak menyelesaikan masalah dengan menggunakan metode Algritma C4.5. 


\section{Metode penelitan}

\section{a. Data mining}

Data Mining adalah proses yang mempekerjakan satu atau lebih teknik pembelajaran computer (machine learning) untuk menganalisa dan mengekstrasi pengetahuan (knowledge) secara otomatis. Data mining merupakan proses iterative dan interaktif untuk menemukan pola atau model baru yang sahih (sempurna), bermanfaat dan dapat dimengerti dalam suatu database yang besar (Hermawati, 2013). Hal penting yang terkait dengan data mining (Kusrini,2019) adalah :

1) Data mining merupakan suatu proses otomatis terhadap data yang sudah ada.

2) Data yang akan diproses berupa data yang sangat besar.

3) Tujuan data mining adalah untuk mendapatkan hubungan atau pola yang mungkin memberikan indikasi yang bermanfaat.[4]

b. Algoritma $C 4.5$

Algoritma C4.5 Merupakan turunan dari metode Classificasion Tree yang digunakan untuk membuat kasifikasi data yang bersifat prediktif, C4.5 salah satu algoritma machine learning Algoritma C4.5 merupakan salah satu algoritma machine learning (Perbandingan, 2017). Dengan algoritma ini akan memberikan sekelompok data yang tidak memiliki label (Unsupervised Learning) yang akan di proses dan ditentukan label sehingga menghasilkan data training, kemudian hasil dari poses data akan digunakan untuk mengelolah data yang baru (data testing), dalam Pengklarasian algoritma C4.5 data testing yang di proses akan menghasilkan sebuah kelas sebagai data Prediction.

c. Pohon Keputusan

Pohon Keputusan Menurut Kusrini dan Luthfi (2009). $\square$ Merupakan Metode klasifikasi dan prediksi yang sangat kuat dan terkenal. Metode pohon keputusan mengubah fakta yang sangat besar menjadi pohon keputusan yang mempresentasikan aturan-aturan dapat dengan mudah dipahami dengan bahasa alami, Dan mereka juga dapat diekpresikan dalam bentuk bahasa basis data seperti Structured Query Languange untuk mencari record pada katagori tertentu $\square .[2]$

d. Langkah - langkah Penyelesaian ALGORITMA C4.5

- Pilih atribut sebagai akar (root).

- $\quad$ Buat cabang pada masing-masing nilai.

- Bagi kasus dalam cabang.

- $\quad$ Ulangi proses untuk masing-masing sampai semua kasus pada cabang memiliki kelas yang sama.[5]

- Entropy merupakan jumlah bit yang dibutuhkan untuk menyatakan suatu kelas, semakin kecil nilai Entropy maka akan semakin Entropy digunakan dalam mengekstrak suatu kelas. Rumus untuk menghitung Entropy adalah sebagai berikut [2]

$$
\text { Entrophy }(\mathrm{s})=\sum_{i=1}^{n}-\mathrm{pi} * \log 2 \mathrm{pi}
$$

$$
\begin{aligned}
& \text { Dimana : } \\
& \mathrm{S} \quad \text { : himpunan kasus } \\
& \mathrm{A} \quad \text { : fitur } \\
& \mathrm{n} \quad \text { : jumlah partisi S } \\
& \text { pi } \quad \text { : proporsi dari Si terhadap S }
\end{aligned}
$$

- Gain merupakan perolehan informasi dari atribut A relative terhadap output data S, Perolehan informasi didapat dari output data atau variable dependent $\mathrm{S}$ yang dikelompokkan berdasarkan atribut A, dinotasikan dengan gain (S.A) Rumus untuk menghitung nilai Gain adalah sebagai berikut[2]

Dimana

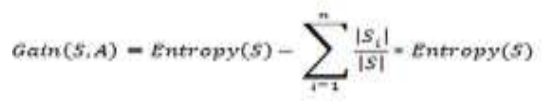

A : Atribut

$\mathrm{S}$ : Sampel

$\mathrm{N}$ : jumlah partisis himpunan atribut $\mathrm{A}$

|Si| : jumlah sampel pada pertisi ke-i

$|\mathrm{S}|$ : jumlah sampel dalam $\mathrm{S}$

\section{Hasil dan Pembahasan}

Penelitian ini menggunakan data simulasi, diasumsi bahwa data yang diterima dari hasil calon pendaftar untuk menentukan terpilihnya menjadi pegawai dibidang pengajar olahraga di sekolah abc dengan memakai data berikut 
ini.

Tabel 1. Kriteria

\begin{tabular}{lllllll}
\hline No & Pendaftar & Usia & Belajar & stamina & mental & KT \\
\hline 1 & Putra & Muda & rutin & Kuat & PD & LLS \\
2 & Fadlan & Muda & rutin & Kuat & gerogi & TDK \\
3 & Angga & Muda & rutin & Lemah & PD & LLS \\
4 & Anto & Muda & jarang & Lemah & PD & LLS \\
5 & agus & Muda & tidakPernah & Lemah & PD & TIDAK \\
6 & Zainab & Tua & rutin & kuat & PD & LLS \\
7 & Fitri & Tua & jarang & lemah & Geroi & TDK \\
8 & Bagus & Muda & rutin & lemah & PD & LLS \\
9 & Rina & Tua & rutin & lemah & Gerogi & TDK \\
10 & Citra & Muda & jarang & lemah & Gerogi & TDK \\
11 & Karim & Muda & rutin & rutin & PD & LLS \\
12 & angel & tua & rutin & rutin & PD & LLS \\
\hline
\end{tabular}

Dari data diatas dihitung nilai Entropy dan Gain untuk masing-masing atribut, dengan menggunakan rumus yang telah disebutkan diatas, seperti pada table berikut ini

Tabel 2. Perhitungan Node 1

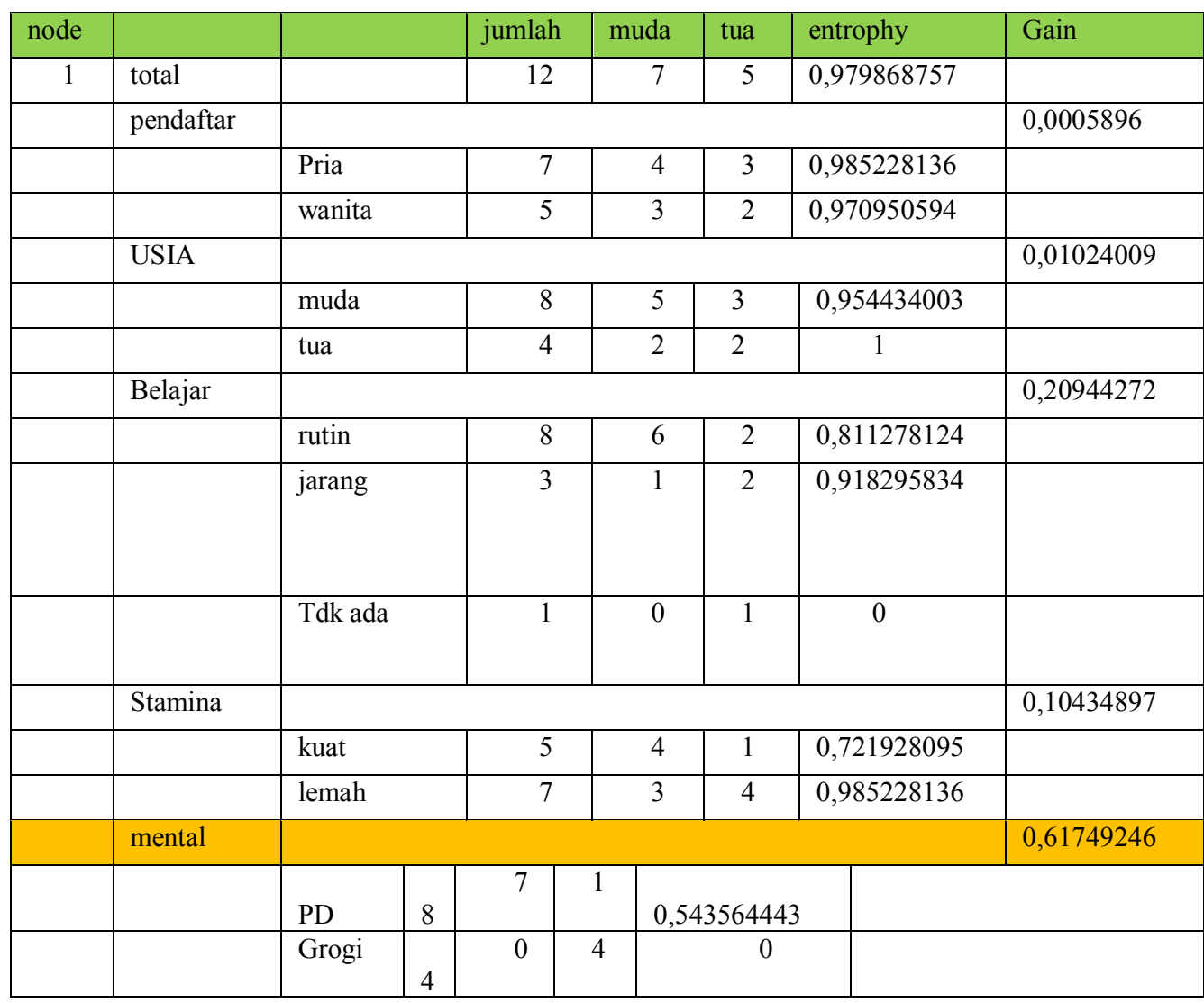

- $\quad$ Jika diantara kolom $\square$ muda $\square$ atau $\square$ tua $\square$ ada yang bernilai 0 (nol) maka entrophy-nya dipastikan juga bernilai 0 (nol)

- $\quad$ Jika kolom $\square$ muda $\square$ dan $\square$ tua $\square$ mempunyai nilai yang sama maka entrophy-nya dipastikan juga bernilai 1 (satu)

Entrophy $($ total $)=(-7 / 12))+(-(5 / 14) *(\log 2(5 / 14)=0,979869$ 
Entrophy (pendaftar (muda) $)=(-(4 / 7) *(\log 2(4 / 7))+((3 / 7) *(\log 2(3 / 7)=0,985228136$

Entrophy (Pendaftar (tua) $)=(-(3 / 5) *(\log 2(3 / 5))+((2 / 5) *(\log 2(2 / 5)=0,970950594,,,$, , dst

Gain (pendaftar $)=0,979869-((7 / 12) * 0,985228136)+((5 / 12) * 0,970950594)=0,0005896,,$, dst

Dari hasil pada table 2. Dapat diketahui bahwa atribut dengan gain tertinggi adalah Mental, Sebesar 0.61749246. Dengan demikian, Mental dapat menjadi node akar, Ada dua nilai atribut dari Mental yaitu PD dan Grogi sudah mengklasifikasi kasus menjadi satu dengan keputusan TDK(Tidak), Sehingga tidak perlu dilakukan perhitungan lebih lanjut, tetapi untuk nilai atribut PD masih perlu perhitungan lagi.

Dari hasil tersebut dapat digambarkan pohon keputusan sementaranya gambar sebagai berikut.

Pohon keputusan dari perhitungan Node 1

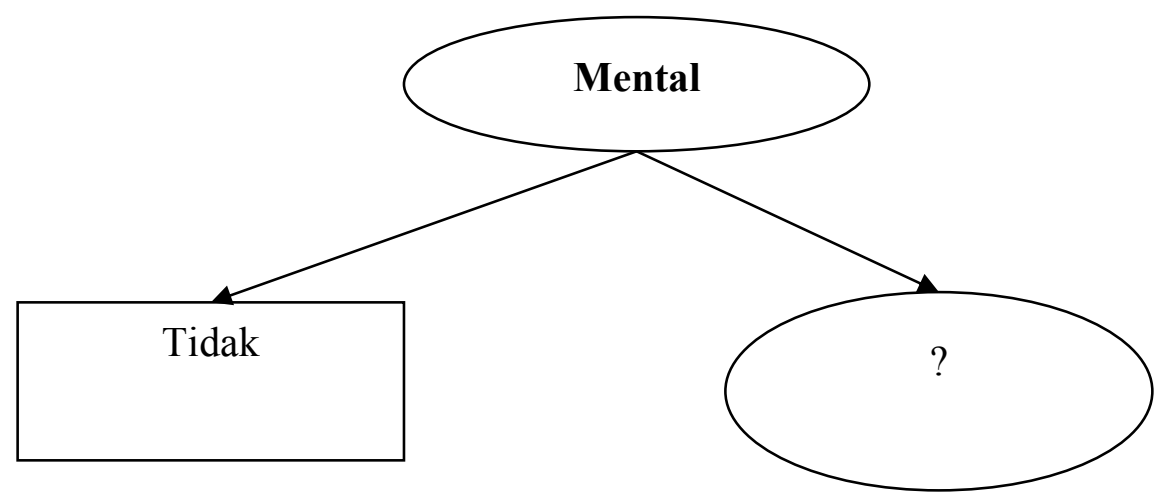

Gambar 1. Phon Keputusan dari perhitungan Node 1

Selanjutnya dihitung nilai Entropy dan Gain untuk masing-masing atribut untuk dapat menjadi node akar dari atribut PD, sebagai berikut:

Tabel 3. Perhitungan Node 1.1

\begin{tabular}{|c|c|c|c|c|c|c|c|}
\hline Node & & & Belajar & Muda & Tua & entropy & Gain \\
\hline \multirow[t]{14}{*}{1.1} & $\begin{array}{l}\text { Mental } \\
\text {-PD }\end{array}$ & & 8 & 7 & 1 & 0,543564443 & \\
\hline & $\begin{array}{l}\text { Pendaft } \\
\text { ar }\end{array}$ & & & & & & 0,09235938 \\
\hline & & Pria & 5 & 4 & 1 & 0,721928095 & \\
\hline & & Wanita & 3 & 3 & 0 & 0 & \\
\hline & Usia & & & & & & 0,05604763 \\
\hline & & Muda & 6 & 5 & 1 & 0,650022422 & \\
\hline & & Tua & 2 & 2 & 0 & 0 & \\
\hline & Belajar & & & & & & 0,54356444 \\
\hline & & Rutin & 6 & 6 & 0 & 0 & \\
\hline & & Jarang & 1 & 1 & 0 & 0 & \\
\hline & & Tidak Ada & 1 & 0 & 1 & 0 & \\
\hline & $\begin{array}{l}\text { Stamin } \\
\mathrm{a}\end{array}$ & & & & & & 0,13792538 \\
\hline & & Kuat & 4 & 4 & 0 & 0 & \\
\hline & & Lemah & 4 & 3 & 1 & 0,811278124 & \\
\hline
\end{tabular}

Dari hasil pada table 3. Dapat diketahui bahwa atribut dengan Gain tertinggi adalah Belajar, yaitu sebesar 0,54356444. Dengan demikian Belajar dapat menjadi node cabang dari nilai atribut PD. Ada tiga nilai atribut dari Belajar yaitu Rutin, Jarang dan Tidak Ada. Dari tiga atribut tersebut, nilai atribut Rutin sudah mengklasifikasi kasus menjadi 1, yaitu keputusannya Muda, nilai atribut Jarang juga sudah mengklasifikasi kasus menjadi 1, Yaitu keputusannya Muda serta nilai atribut Tidak ada juga sudah mengklasifikasi kasus menjadi 1, yaitu keputusannya Tidak Sehingga tidak perlu dilakukan perhitungan lebih lanjut. Dengan demikian Diperolehlah pohon keputusannya sebagai berikut dan dapat dilihat pada gambar 3 :

\section{Mental}




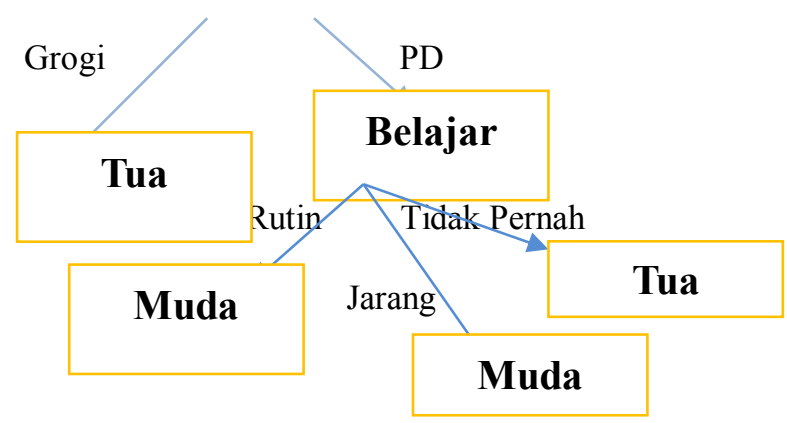

Gambar 2. dari pohon Keputusan Terakhir Yang sudah berbentuk

\section{Kesimpulan}

Data mining dan algoritma C4.5 sangat berguna dan memudahkan dalam pengambilan keputusan yang efektif dengan memproyeksikan data-data yang ada ke dalam bentuk phon keputusan, berdasarkan nilai entropy dan gain yang dimiliki masing-masing atribut data. Algoritma C4.5 membantu menentukan beberapa pegawai yang masuk dalam kreteria yang sudah di tentukan, Berdasarkan dari hasil penelitian

\section{Referensi}

[1] R. Mulyana, A. Pendahuluan, and M. A. Naess, $\square$ PENANAMAN ETIKA LINGKUNGAN MELALUI, $\square$ vol. 6, no. 2, pp. $175 \square 180,2009$.

[2] P. T. Prismas, J. Jakarta, A. Asistyasari, and T. Baidawi, $\square$ ANALISIS PENERIMAAN KARYAWAN POSISI FIELD COLLECTOR MENGGUNAKAN ALGORITMA C4 . 5 PADA, $\square$ vol. 2, no. 2, pp. 1 $\square 6,2017$.

[3] F. F. Harryanto, S. Hansun, U. M. Nusantara, G. Serpong, and C. Pegawai, $\square$ Penerapan Algoritma C4 . 5 untuk Memprediksi Penerimaan Calon Pegawai Baru di PT WISE, $\square$ vol. 3, no. 2, pp. 95 $\square$ 103, 2017.

[4] D. Listriani, A. H. Setyaningrum, and F. E. M. A, $\square$ PENERAPAN METODE ASOSIASI MENGGUNAKAN ALGORITMA APRIORI PADA APLIKASI ANALISA POLA BELANJA KONSUMEN ( Studi Kasus Toko Buku Gramedia Bintaro ), $\square$ J. Tek. Inform. Vol 9 No. 2, Univ. Islam Negeri Jakarta, vol. 9, no. 2, pp. 120 $\square 127,2016$.

[5] I. Sembiring, $\square$ Pengambilan keputusan pegawai tidak tetap menjadi pegawai tetap dengan decission tree, $\square$ vol. 1, pp. $26 \square 37,2018$ 